\title{
Recovery pathways from small-scale disturbance in a temperate Australian seagrass
}

\author{
Timothy M. Smith ${ }^{1,5, *}$, Paul H. York ${ }^{1,2,5}$, Peter I. Macreadie ${ }^{3,4}$, Michael J. Keough $^{5}$, \\ D. Jeff Ross ${ }^{6}$, Craig D. H. Sherman ${ }^{1}$ \\ ${ }^{1}$ School of Life and Environmental Sciences, Centre for Integrative Ecology, Deakin University (Waurn Ponds Campus), \\ 75 Pigdons Road. Locked Bag 20000, Geelong, VIC 3220, Australia \\ ${ }^{2}$ Centre for Tropical Water \& Aquatic Ecosystem Research (TropWATER), James Cook University, PO Box 6811, Cairns, \\ QLD 4870, Australia \\ ${ }^{3}$ School of Life and Environmental Sciences, Centre for Integrative Ecology, Deakin University (Burwood Campus), \\ 221 Burwood Highway, Burwood, VIC 3125, Australia \\ ${ }^{4}$ Plant Functional Biology and Climate Change Cluster (C3), School of the Environment, University of Technology Sydney, \\ Broadway, NSW 2007, Australia \\ ${ }^{5}$ School of BioSciences, University of Melbourne, Melbourne, VIC 3010, Australia \\ ${ }^{6}$ Institute for Marine and Antarctic Studies, University of Tasmania, Taroona, TAS 7053, Australia
}

\begin{abstract}
Recovery from disturbance is a key element of ecosystem persistence, and recovery can be influenced by large-scale regional differences and smaller local-scale variations in environmental conditions. Seagrass beds are an important yet threatened nearshore habitat and recover from disturbance by regrowth, vegetative extension and dispersive propagules. We described recovery pathways from small-scale disturbances in the seagrass Zostera nigricaulis in Port Phillip Bay, a large embayment in southeastern Australia, and tested whether these pathways differed between 5 regions with different hydrodynamic conditions and water quality, and between sites within those regions. Recovery pathways were broadly consistent. When aboveground biomass was removed, recovery, defined as the point at which disturbed areas converged with undisturbed controls, took from 2 to $8 \mathrm{mo}$, but when we removed above- and below-ground biomass, it took between 2 and 13 mo. There was no evidence of recovery resulting from sexual reproduction at any sites regardless of the presence of seeds in the sediment or flower production. We found no differences in recovery at the regional scale, but we found substantial differences between local sites. At some sites, rapid recovery occurred because seagrasses grew quickly, but at others, apparent recovery occurred because regrowth coincided with overall declines in cover of undisturbed areas. Recovery time was unrelated to seagrass canopy height, biomass, percentage cover, stem density, seed bank density, epiphyte cover or sediment organic matter in seagrass adjacent to disturbance experiments. This study highlights the importance of understanding fine-scale variation in local recovery mechanisms, which may override or obscure any regional signal.
\end{abstract}

KEY WORDS: Zostera nigricaulis · Port Phillip Bay · Sexual reproduction · Asexual reproduction · Resilience $\cdot$ Spatial scales $\cdot$ Heterozostera nigricaulis

Resale or republication not permitted without written consent of the publisher

\section{INTRODUCTION}

As habitat loss increases and ecosystem health declines, understanding resilience to disturbance is becoming increasingly important. This information is particularly needed along urbanised coasts, where there are concerns that a range of human activities may reduce resilience (Hughes et al. 2010, Holon et al. 2015). Simultaneously, resource managers are being urged to take actions that increase resilience of coastal ecosystems (Folke et al. 2004, Adger et al. 2005). A prerequisite for managing resilience is an 
understanding of how recovery occurs, including the potential for shifts to alternative ecosystem or community states and the rates and extent of recovery (Andersen et al. 2009, Fukami \& Nakajima 2011). Typically, these issues are of particular concern around large population centres, where there may be strong spatial variation in anthropogenic influences alongside natural environmental variation. Under these circumstances, we need to know how this variation affects recovery rates. At large spatial scales, regional environmental processes can modify localscale recovery patterns, having a direct influence on recruitment and community structure (Navarrete et al. 2005, Bryson et al. 2014, Martins et al. 2014). Understanding the spatial variation in resilience and whether this variation occurs at local or regional scales is vitally important in managing natural systems (Anthony et al. 2015).

Seagrass habitats exemplify these concerns. Seagrasses are marine angiosperms that have suffered an estimated $29 \%$ global loss (Waycott et al. 2009), with $14 \%$ of all species facing extinction (Short et al. 2011). They play a number of important ecosystem roles, including habitat stabilisation, maintaining water quality, nutrient cycling, carbon sequestration, and provision of habitat for fish and invertebrates (Orth et al. 2006a, Barbier et al. 2011, Macreadie et al. 2014a). Seagrass loss can occur through largescale disturbances such as eutrophication, disease, light reduction, sedimentation and high water temperatures, and at smaller scales via herbivory, dredging, propeller scarring, bioturbation, erosion and wave action (Orth et al. 2006a).

An important component of resilience is the capacity to recover from disturbances (Folke et al. 2004). Seagrass recovery may take months to decades depending on the scale, magnitude and location of the disturbance event and the species affected. For example, a wasting disease that decimated North Atlantic Zostera marina populations, including local extinctions in the 1930s, took decades to recover in Denmark and in Chesapeake Bay, USA (Frederiksen et al. 2004, Orth et al. 2006b), whereas recovery of Zostera muelleri to small-scale mechanical disturbances in Australia took only a few months (Macreadie et al. 2014b). Even within the same location, recovery times for a given species can vary with water depth (i.e. subtidal versus intertidal) (Boese et al. 2009, Macreadie et al. 2014c, Rasheed et al. 2014), and, in mixed beds (i.e. multiple species), colonising specialists are able to recover more quickly before being outcompeted by larger, more robust species (Rasheed 2004).
As clonal organisms, seagrasses can use several pathways to recover from disturbance. When only aboveground biomass is lost, they can reshoot from belowground reserves, and if both above- and belowground biomass is lost, seagrasses can expand vegetatively from disturbance edges via new shoots and rhizome extensions (Rasheed 1999, 2004). They also produce dispersive propagules, most commonly seeds, but also drifting fragments (Kendrick et al. 2012). Seeds may be dispersed into a disturbed area, or they may germinate from seed banks in the sediment, leading to seagrass recovery (Rasheed et al. 2014). Recovery speed and pathways may affect the ability of seagrass to return to pre-disturbance state and maintain resilience to further disturbance.

In this study, we focus on recovery pathways in the temperate seagrass Zostera nigricaulis (formerly Heterozostera tasmanica; Jacobs \& Les 2009) in a large embayment in southeastern Australia. The bay shows considerable variations in environmental and nutrient conditions. It is hydrodynamically complex, ranging from tidally driven circulation in coarse sediments in the south to weaker, wind-driven patterns in northern and western areas, with associated fine sediments. We aimed to (1) determine pathways by which seagrasses recover from small-scale disturbances in Port Phillip Bay; (2) test whether there are regional differences in seagrass recovery; and (3) assess biotic and abiotic factors that may affect seagrass recovery.

\section{MATERIALS AND METHODS}

\section{Study site}

This study was undertaken in Port Phillip Bay, southeastern Australia. Port Phillip Bay is a large (around $2000 \mathrm{~km}^{2}$ ), relatively shallow (more than $50 \%$ is $<8 \mathrm{~m}$ deep), semi-enclosed bay. It is partially surrounded by the cities of Melbourne and Geelong, with the largest urban concentration to the north. There is a large wastewater treatment plant with a shoreline discharge on the western side, along with a substantial catchment input to the north and several smaller inputs. Port Phillip Bay has a long history of disturbance, including dredging and coastal modification. Zostera nigricaulis covers approximately $65 \mathrm{~km}^{2}$ and is the dominant structured habitat in Port Phillip Bay (Blake \& Ball 2001). Seagrass habitats around Port Phillip Bay can be divided into 5 different regions, based on combinations of hydrodynamics and anthropogenic activities: northern Port Phillip 
Bay (North), southern Port Phillip Bay (South), Corio Bay, Swan Bay and the Geelong Arm. Within each region, 2 sites were chosen for seagrass disturbance experiments (Fig. 1). The coastline in the northern region of the bay is extremely modified, sediments are relatively fine, and there are high nutrient inputs from the Western Treatment Plant and Yarra River. The southern region of the bay is characterised by patchy, dense seagrass in coarse sand and has experienced significant seagrass decline over the past decade. This region is exposed to oceanic water input from Bass Strait. Swan Bay is an extensive seagrass meadow that receives little water exchange, low nutrient inputs and has high epiphyte abundances. Seagrass in Corio Bay forms large persistent seagrass meadows with low nutrient input and wave exposure. In the Geelong Arm, seagrass forms variable sized patches and is exposed to wave action and sediment movement in the south, where there has been recent seagrass loss and elevated nutrient loads from the Western Treatment Plant in the north (Walker 1999, Lee et al. 2012, Ball et al. 2014, A. J. Hirst unpubl. data).

\section{Experimental design}

Five treatments were used to determine the recovery time and mechanisms after disturbances of different magnitudes: (1) control treatments with no seagrass removal, including undisturbed areas and

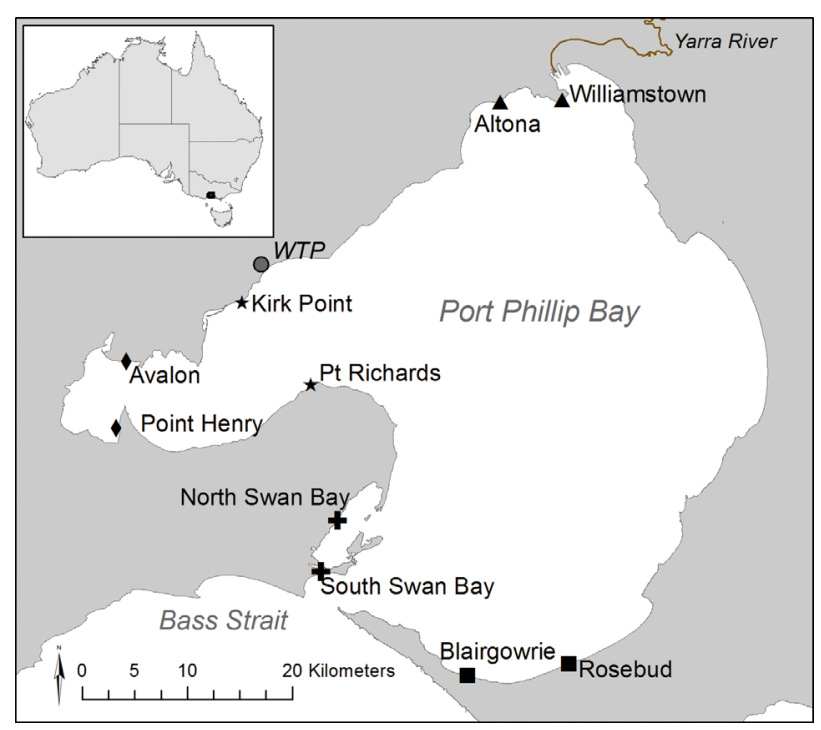

Fig. 1. Experimental sites within 5 regions in Port Phillip Bay, southeastern Australia: $\boldsymbol{\Delta}$ : northern Port Phillip Bay (North);

口: southern Port Phillip Bay (South); +: Swan Bay; Corio Bay; $\star$ : Geelong Arm; WTP: Western Treatment Plant procedural controls, where we added a physical border; (2) regrowth by shoots-seagrass with aboveground plant material removed; (3) asexual regeneration-seagrass with above- and belowground plant material removed, but asexual growth from the edge allowed; and (5) sexual regeneration - seagrass with above- and belowground plant material removed and a border placed to prevent rhizome encroachment.

The aboveground-only removal represents a low intensity disturbance (e.g. herbivore grazing), whereas the above- and belowground removal represent a high intensity disturbance, typical of mechanical damage (e.g. boat propeller scarring). The removal of plant material in high intensity disturbance treatments often left a depression in the sediment; however, changes to sediment height were only minimal or returned to pre-disturbance levels within a few months. Each disturbance plot was a $300 \mathrm{~mm}$ diameter circle $\left(\right.$ area $\left.=0.07 \mathrm{~m}^{2}\right)$. Borders (made from PVC piping) were inserted to a depth of $95 \mathrm{~mm}$, leaving $5 \mathrm{~mm}$ of border exposed above the sediment surface, and plastic stakes marked each treatment. At each site, 3 blocks $(\sim 2 \times 2 \mathrm{~m})$ were established at least $20 \mathrm{~m}$ apart and at a depth of $\sim 0.5 \mathrm{~m}$ mean low water spring tide (MLWS), with a replicate of each disturbance treatment placed haphazardly within each block.

\section{Monitoring}

Experimental treatments were monitored every month for the first $6 \mathrm{mo}$ and then every $3 \mathrm{mo}$, and concluded after a total of 14 mo from the initial disturbance (November 2011). Sampling involved visually estimating percent cover (using Seagrass-Watch standard protocols, which involved 2 observers and use of a percent cover photograph standard; McKenzie et al. 2003) and seagrass canopy height (at the longest point) in each replicate plot. Seedlings were identified as single seagrass shoots not attached to rhizomes extending from existing plants. During monitoring, plots were inspected for rhizomes growing over the top of borders into plots. On rare occasions where rhizome jumping had occurred (as detected by tracing plants within plots to their origin outside of plots), these plants were removed.

To characterise patch conditions at each site over time, several variables were measured every 3 mo. Replicate $0.5 \mathrm{~m}^{2}$ quadrats were placed haphazardly within seagrass beds adjacent to each block $(n=3)$ to estimate percent cover, canopy length and epiphyte 
cover. Within each quadrat, all the seagrass within a $0.065 \mathrm{~m}^{2}$ sub-quadrat was cut at the sediment surface and stored for processing in the laboratory. A $10 \mathrm{~cm}$ diameter core to $10 \mathrm{~cm}$ depth was taken from the area where seagrass had been removed, and was returned to the laboratory for processing. In the laboratory, the number of woody stems in each sample was recorded for aboveground samples to estimate stem density. All epiphytes were removed and dried separately from seagrass in an oven at $60^{\circ} \mathrm{C}$ for $48 \mathrm{~h}$ before being weighed to estimate aboveground and epiphyte biomass. Reproductive effort was also estimated by counting flowering inflorescences (spathes) present on aboveground samples. Sediment cores were sieved through 2000 and $710 \mu \mathrm{m}$ sieves, and all sediment captured in the $710 \mu \mathrm{m}$ sieve was inspected for seeds to estimate seed density. All living seagrass material in the $2000 \mu \mathrm{m}$ sieve was dried in an oven at $60^{\circ} \mathrm{C}$ for $48 \mathrm{~h}$ before being weighed to estimate belowground biomass.

Sediment and water temperature data were collected from each site to determine whether local environmental conditions affected seagrass recovery. At each site, 3 sediment cores $(\approx 50 \mathrm{~g})$ were sampled at the initiation of the experiment to determine organic matter content and sediment grain size. Once collected, cores were sieved through 500 and $250 \mu \mathrm{m}$ sieves, dried and weighed to determine the proportion of coarse $(>500 \mu \mathrm{m})$, medium $(500-250 \mu \mathrm{m})$ and fine $(<250 \mu \mathrm{m})$ sand. Organic matter content was determined using the methods described by Erftemeijer \& Koch (2001). Water temperature was recorded hourly by HOBO data loggers (Onset Computer Corperation) attached to stakes at each site. Temperature was recorded from 30 November 2011 to 20 February 2012, 1 May to 20 July 2012 and 1 October to 10 December 2012 to represent seasonal changes in water temperature.

\section{Data analysis}

We examined recovery profiles using linear mixed models incorporating repeated measures. Data analyses were performed using SYSTAT Ver. 13, and percentage cover data were arcsine transformed. A model was fitted with regions (fixed effect, 5 levels), sites (random effect, nested within regions, 2 levels), treatments (fixed effect, 5 levels, and crossed with region and site), block (random effect, nested within site) and time (fixed effect, 7 levels). Time was the repeated factor. For this analysis, the 2 effects of interest were the region $\times$ treatment $\times$ time and site $\times$ treatment $\times$ time effects, which reflect spatially variable recovery at 2 different scales. The sexual recovery treatment did not recover at any sites but was included in the initial analysis, relying on the model's robustness to variance heterogeneity, to demonstrate clear treatment effects before it was removed for further analysis.

Recovery profiles varied strongly among sites, and we explored this pattern by examining each treatment separately. We did this for 4 treatments (excluding the sexual regeneration plots), fitting a simpler repeated-measures design that included regions, site(region), block(site(region)) and time.

To understand patterns of variation among sites, we also identified the time at which disturbed plots converged with controls, by running ANOVA at each site-time combination, and from this analysis we ran planned comparisons to assess the recovery time via asexual reproduction (asexual versus controls) and shoot regrowth (regrowth versus controls). Convergence was considered to have occurred if there was no statistically significant difference between the relevant disturbance treatment and the controls for 2 consecutive sampling periods.

For maximum canopy height, we used a simpler analysis because it was not possible to measure canopy height in the early stages of recovery. We analysed 3 sampling times $(3,6$ and $12 \mathrm{mo})$, corresponding to times when some sites had recovered. At each time, we fitted a partly nested model with region, site(region), block(site(region)) and treatment.

\section{Data screening}

During the experiment, seagrass cover declined to zero in some plots at Avalon and Blairgowrie from initial moderate to high values. We ran 2 versions of our data analysis, one with all available plots, and one in which a plot was excluded once its cover dropped to zero. This had no effect on our overall results and only affected our estimate of convergence/recovery time for one site. We also had blocks vandalised at 2 sites, but this happened in the latter stages of the experiment. Data from these stages are presented for illustration, but were not included in formal analyses.

\section{Seagrass patch characteristics}

Regression analysis was used to determine whether any seagrass patch characteristics for which 
data were collected contributed to seagrass recovery. Months to recovery at each site was treated as a dependent variable for both the regrowth and asexual recovery treatments in separate analyses. Initial canopy length, above- and belowground biomass, epiphyte cover, sediment organic content, grain size and temperature were averaged for each site and used as independent variables in separate analysis. Patch characteristics (canopy height, above- and belowground biomass, epiphyte cover, and seed, spathe and stem density) were collected every 3 mo (total of 6 times). A partly nested ANOVA design was used to assess whether patch characteristics changed across regions and sampling times. Region (5 levels) and sampling time (crossed with region and site, 6 levels) were treated as fixed factors and site (nested within regions, 2 levels) was treated as a random factor. Only October samples (when flowering occurred) were used for spathe data. Point Henry stem density, and aboveground and epiphyte biomass were not sampled in January 2013, but were substituted with December 2012 data (Jenkins et al. 2015). Williamstown was not sampled in October 2011 and therefore the average of all Williamstown samples was used to complete the dataset (Quinn \& Keough 2002). Organic matter and sediment grain size were only sampled at the beginning of the experiment and therefore were analysed using a nested ANOVA using region as a main effect and site nested within region as a random factor. Sediment data was arcsine transformed.

\section{RESULTS}

Seagrass recovery from small-scale disturbances varied with region, site and disturbance treatment, with the exception of the sexual regeneration treatment, which showed no recovery after 7 mo regardless of site. Percentage cover showed a significant interaction between both time $x$ treatment $x$ region and time $\times$ treatment $\times$ site(region) (Table 1). Further investigation revealed no significant regional variation for each treatment (region $\times$ time, $\mathrm{p}=$ $0.886,0.684,0.745$ and 0.126 for undisturbed and procedural controls, regrowth and asexual treatments, respectively), but significant variation among sites (time $\times$ site, $\mathrm{p}<0.001$ for controls and asexual treatments and $\mathrm{p}=0.019$ for regrowth, Fig. 2) for percent cover. Recovery time for low (regrowth) and high intensity (asexual recovery) treatments showed no particular pattern among regions, but did vary substantially between sites (Table 2).
Table 1. Repeated-measures ANOVA comparing percent seagrass Zostera nigricaulis cover across treatments, regions, sites and time to disturbance after 6 mo. Significant values are in bold $(\mathrm{p}<0.05)$

\begin{tabular}{|lrrr|}
\hline & df & $F$ & $\mathrm{p}$ \\
\hline Between subjects & & & \\
Region & 4 & 0.18 & 0.942 \\
Treatment & 4 & 39.09 & $<\mathbf{0 . 0 0 1}$ \\
Plot & 2 & 0.56 & 0.573 \\
Treatment $\times$ Region & 16 & 0.77 & 0.697 \\
Site $($ Region) & 5 & 15.38 & $<\mathbf{0 . 0 0 1}$ \\
Treatment $\times$ Site $($ Region) & 20 & 2.54 & $\mathbf{0 . 0 0 2}$ \\
Error & 85 & & \\
Within subjects & & & \\
Time & 6 & 3.36 & $\mathbf{0 . 0 0 3}$ \\
Time $\times$ Region & 24 & 3.99 & $<\mathbf{0 . 0 0 1}$ \\
Time $\times$ Treatment & 24 & 21.74 & $<\mathbf{0 . 0 0 1}$ \\
Time $\times$ Plot & 12 & 0.83 & 0.620 \\
Time $\times$ Treatment $\times$ Region & 96 & 1.33 & $\mathbf{0 . 0 2 9}$ \\
Time $\times$ Site $($ Region) & 30 & 6.22 & $<\mathbf{0 . 0 0 1}$ \\
Time $\times$ Treatment $\times$ Site(Region) & 120 & 1.44 & $\mathbf{0 . 0 0 4}$ \\
Error & 510 & & \\
\hline
\end{tabular}

The quickest recovery of low intensity disturbance took 2 mo at Altona, Williamstown, Blairgowrie and North Swan Bay, and the slowest was at South Swan Bay $(8 \mathrm{mo})$. Seagrass exposed to high intensity disturbance took longer to recover than seagrass exposed to low intensity disturbance at all sites except Altona and Blairgowrie, where asexual treatments also recovered in $2 \mathrm{mo}$, much shorter than the 13 mo it took to recover at Point Richards and South Swan Bay.

After 3 mo, seagrass canopy height had not fully recovered, as high and low intensity disturbance treatments (asexual and regrowth treatments) were significantly shorter than controls (Table 3, Fig. 3). There was a significant regional effect where canopy height in the Geelong Arm was greater than that of seagrass in North and Swan Bay. After 6 mo there was a significant treatment $\times$ region interaction. There was no difference in canopy height across treatments in North, South and Swan Bay, indicating that they had recovered. Canopy height in the Geelong Arm and Corio Bay had not fully recovered, with high intensity disturbance treatments shorter than controls in the Geelong Arm and low intensity disturbance plots shorter than controls in Corio Bay. In Corio Bay, however, there was only a single height measurement in the asexual treatments indicating that all other plots had zero cover and had not recovered. After 12 mo there was no significant difference between any of the treatments. 

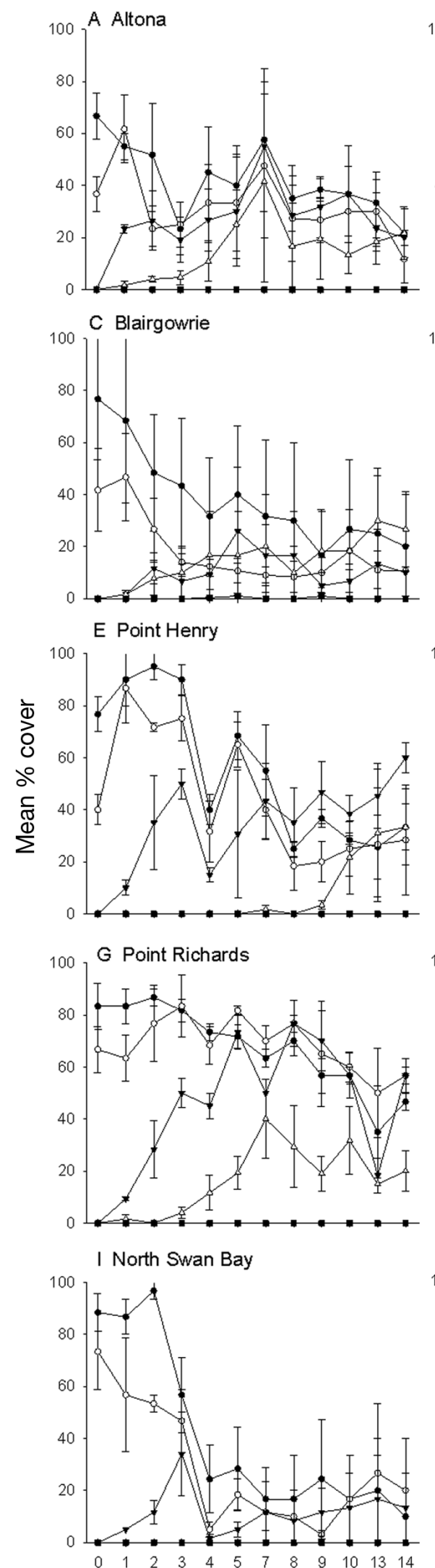

Months since disturbance

\section{Seagrass patch characteristics}

Spathes and seeds in seagrass surrounding experimental plots were sampled at all sites where experiments took place, with the highest abundance found at Point Henry (mean \pm SE $11312 \pm 1553$ seeds $\mathrm{m}^{-2}, 2496 \pm 1369$ spathes $\mathrm{m}^{-2}$ ) but very few at Altona (68 \pm 62 seeds $\mathrm{m}^{-2}, 45.3 \pm 26$ spathes $\mathrm{m}^{-2}$ ) and Williamstown $(402 \pm 105,101 \pm$ 45). There were no significant differences across regions or sampling time for either seed or spathe density, although seed density varied across sites (Table 4). Some seagrass properties in seagrass adjacent to experiments, however, did decline throughout the course of the experiment. Canopy height, stem density and biomass all declined over time (Table 4, Fig. 4). Canopy height was greater in October 2011 and January 2012 when the experiment started compared with the last 2 sampling times (October 2012, January 2013), and was greater in April 2012 than January 2013. Similarly, stem density was greater in October 2011 than October 2012 and January 2013, and in both January and April 2012 than January 2013. Aboveground seagrass biomass was greater in October 2011 than April, June and October 2012 and January 2013, and in January 2012 than January 2013. Seagrass canopy height also varied across regions: Corio Bay had longer seagrass than North, South and Swan Bay, but not Geelong Arm, and Geelong Arm had longer seagrass than Swan Bay (Fig. 4). There was no difference in percent sediment organic matter $\left(F_{4,20}\right.$ $=1.888, \mathrm{p}=0.251)$ or coarse $\left(F_{4,20}=\right.$ $0.305, \mathrm{p}=0.863)$, medium $\left(F_{4,20}=2.488\right.$, $\mathrm{p}=0.172)$ or fine sand $\left(F_{4,20}=1.912, \mathrm{p}=\right.$ 0.247 ) across regions, but there were differences between sites within re-

Fig. 2. Mean percent cover for seagrass Zostera nigricaulis undisturbed control $(\bullet)$, procedural control $(\mathrm{O})$, regrowth $(\boldsymbol{\nabla})$, asexual $(\Delta)$ and sexual $(\boldsymbol{\square})$ treatments over months since disturbance for each region and site 
Table 2. Comparison between percent cover in seagrass asexual (A) and regrowth $(\mathrm{R})$ treatments and the control treatments for each month after the initial disturbance. Recovery was considered to have occurred when the particular treatment was not distinguishable from controls for 2 consecutive samples. PPB: Port Phillip Bay. Asterisks indicate a significant difference $(p<0.05)$

\begin{tabular}{|c|c|c|c|c|c|c|c|c|c|c|c|c|c|c|c|c|c|}
\hline \multirow{3}{*}{$\begin{array}{l}\text { Time since } \\
\text { disturbance } \\
\text { (mo) }\end{array}$} & \multicolumn{4}{|c|}{ - North PPB -} & \multicolumn{4}{|c|}{ — Corio Bay — } & \multicolumn{4}{|c|}{ Geelong Arm } & \multicolumn{3}{|c|}{ — South PPB - } & \multicolumn{2}{|c|}{$\longrightarrow$ Swan Bay } \\
\hline & \multicolumn{2}{|c|}{ Altona } & \multicolumn{2}{|c|}{$\begin{array}{l}\text { Williams- } \\
\text { town }\end{array}$} & \multicolumn{2}{|c|}{ Avalon } & \multicolumn{2}{|c|}{$\begin{array}{c}\text { Pt } \\
\text { Henry }\end{array}$} & \multicolumn{2}{|c|}{$\begin{array}{c}\text { Kirk } \\
\text { Pt }\end{array}$} & \multicolumn{2}{|c|}{$\begin{array}{c}\text { Pt } \\
\text { Richards }\end{array}$} & \multicolumn{2}{|c|}{$\begin{array}{l}\text { Blair- } \\
\text { gowrie }\end{array}$} & $\begin{array}{l}\text { Rose- } \\
\text { bud }\end{array}$ & $\begin{array}{c}\text { South } \\
\text { Swan Bay }\end{array}$ & $\begin{array}{c}\text { North } \\
\text { Swan Bay }\end{array}$ \\
\hline & A & $\mathrm{R}$ & & $\mathrm{R}$ & A & $\mathrm{R}$ & $\mathrm{A}$ & $\mathrm{R}$ & A & $\mathrm{R}$ & A & $\mathrm{R}$ & A & $\mathrm{R}$ & A $R$ & A $\mathrm{R}$ & A $\mathrm{R}$ \\
\hline 1 & * & * & * & * & * & * & * & * & * & * & * & * & * & * & * * & & * $\quad$ * \\
\hline 2 & & & * & & & & * & * & * & * & * & * & & & & * $\quad$ & * $\quad$ * \\
\hline 3 & & & * & & * & * & * & * & * & * & * & * & & & * & * & * \\
\hline 4 & & & & & * & * & * & * & * & & * & * & & & & & * $\quad$ * \\
\hline 5 & & & & & & & * & & * & & * & & & & & & * $\quad$ * \\
\hline 7 & & & & & & & * & & & & * & & & & & & * $\quad$ * \\
\hline 8 & & & & & & & & & * & & * & & & & & & * \\
\hline 9 & & & & & & & * & & * & * & * & & & & & & * \\
\hline 10 & & & & & & & & & & & * & & & & & & * \\
\hline 13 & & & & & & & & & & * & & & & & & & \\
\hline 14 & & & & & & & & & & & * & & & & & & \\
\hline
\end{tabular}

Table 3. ANOVA results comparing seagrass canopy height across treatments, regions, and sites at 3,6 and 12 mo after disturbance. Significant values are in bold $(\mathrm{p}<0.05)$

\begin{tabular}{|lrrrrrrrr|}
\hline & df & \multicolumn{2}{c}{3 mo } & \multicolumn{2}{c}{6 mo } & \multicolumn{2}{c|}{12 mo } \\
& & \multicolumn{1}{c}{$F$} & $\mathrm{p}$ & \multicolumn{1}{c}{$F$} & $\mathrm{p}$ & $F$ & $\mathrm{p}$ \\
\hline Region & 4 & 5.913 & $\mathbf{0 . 0 3 9}$ & 2.327 & 0.190 & 0.848 & 0.551 \\
Treatment & 3 & 15.736 & $<\mathbf{0 . 0 0 1}$ & 11.063 & $<\mathbf{0 . 0 0 1}$ & 2.949 & 0.069 \\
Region $\times$ Treatment & 12 & 1.238 & 0.353 & 3.051 & $\mathbf{0 . 0 2 8}$ & 0.886 & 0.579 \\
Site(Region) & 5 & 1.355 & 0.283 & 1.224 & 0.341 & 4.625 & $\mathbf{0 . 0 0 8}$ \\
Treatment $\times$ Site(Region) & 14 & 0.989 & 0.494 & 0.168 & 0.999 & 0.560 & 0.859 \\
Block(Site(Region)) & 16 & 1.599 & 0.103 & 2.415 & 0.015 & 1.601 & 0.119 \\
Error & 36 & & & & & & \\
\hline
\end{tabular}

gions (organic matter $\mathrm{F}_{5,20}=5.709, \mathrm{p}=0.002$, coarse sand $\mathrm{F}_{5,20}=2.767, \mathrm{p}=0.047$, medium sand $\mathrm{F}_{5,20}=$ $4.073, p=0.010$, fine sand $\left.F_{5,20}=4.557, p=0.006\right)$. No significant relationship was found between any seagrass patch variable we measured and recovery time for regrowth or asexual recovery (Table 5).

\section{DISCUSSION}

There was no evidence that seagrass recovered from seeds at any site. Instead, recovery occurred through asexual growth. Even at sites with abundant seed banks and flowering individuals, there was no recovery in bordered treatments where rhizomes were excluded, even after 14 mo. The experimental treatments continued to be maintained after this period, and after 25 mo there was still no evidence of recovery from seeds (T.M.S. unpubl. data). These results support previous studies using similar methods that found no recovery from seeds (Rasheed 1999, 2004, Boese et al. 2009, Macreadie et al. 2014b), but contrast to those of natural disturbances that have found seeds to be important sources of recovery (Plus et al. 2003, Olesen et al. 2004, Zipperle et al. 2009, Becheler et al. 2010).

There are several factors that may explain why recovery did not occur through sexual reproduction in Port Phillip Bay. The absence of seeds within treatment plots is an obvious explanation at some sites, but it is unlikely at sites such as Point Henry, Blairgowrie and Point Richards, where the abundance of seeds in the seed bank can exceeded 9000 seeds $\mathrm{m}^{-2}$. High seed density does not necessarily equate to high germination, and seed quality and environmental conditions may restrict germination and seedling survival. Factors including burial depth, anoxia, sediment type and temperature can affect Zostera seed germination and viability (Moore et al. 1993, Conacher et al. 1994, Jarvis \& Moore 2015), and reduced light levels can affect seedling survival (Bintz \& Nixon 2001). During the initial removal of rhizomes and consequent redistribution of sediment, seeds may have been exposed to anoxic or incompatible sediment, buried at depths that prohibit germination or, if germination occurs, shaded by surrounding seagrass, preventing any recovery. Environmental conditions required for seed germination may not have occurred during the experiment and, if left for a greater period of time, germination conditions may have occurred, allowing sexual recovery. Seed banks in Zostera species are typically maintained through annual flowering (Orth et al. 2000, Jarvis \& 

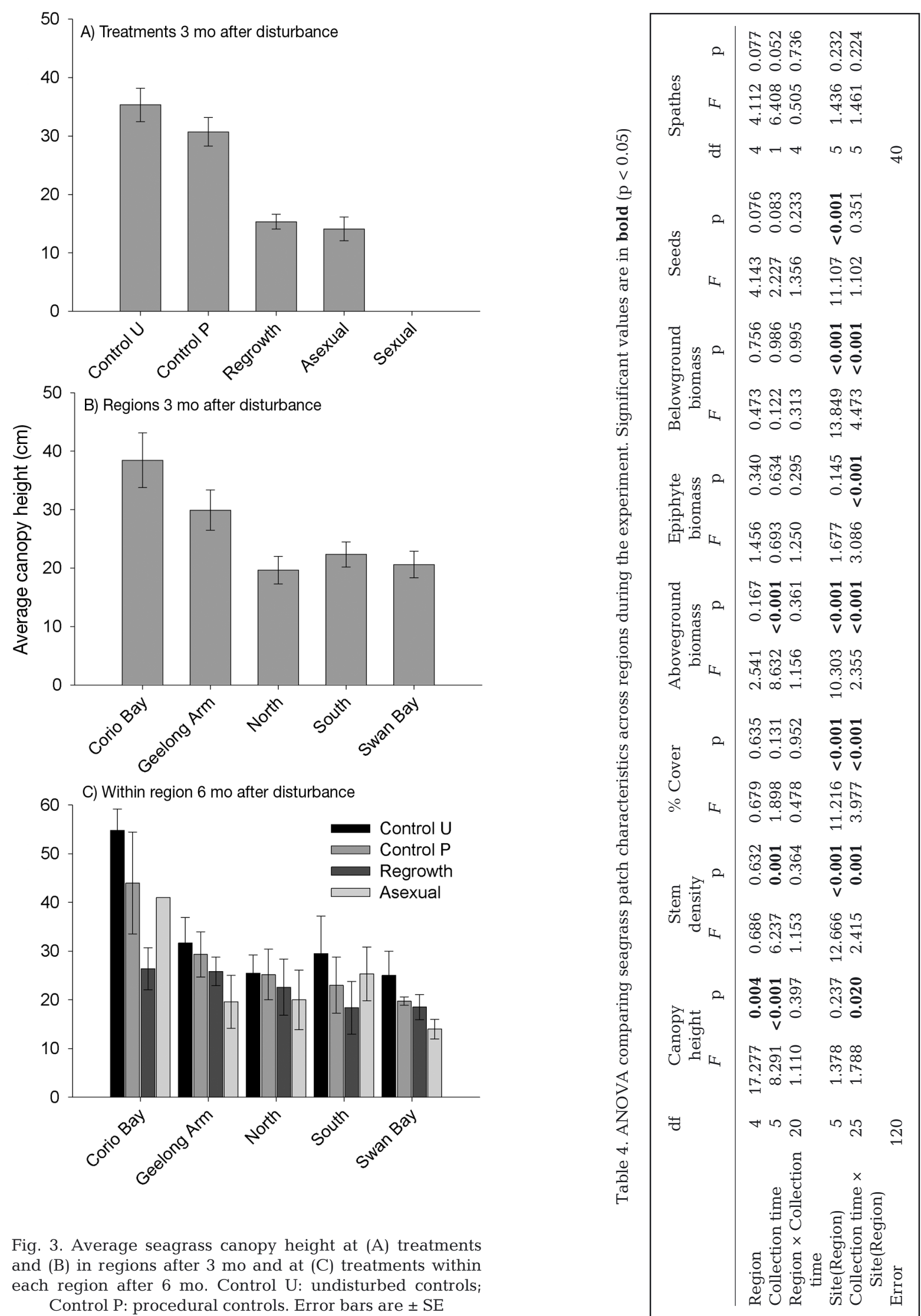

Fig. 3. Average seagrass canopy height at (A) treatments and (B) in regions after 3 mo and at (C) treatments within each region after 6 mo. Control U: undisturbed controls; Control P: procedural controls. Error bars are \pm SE 

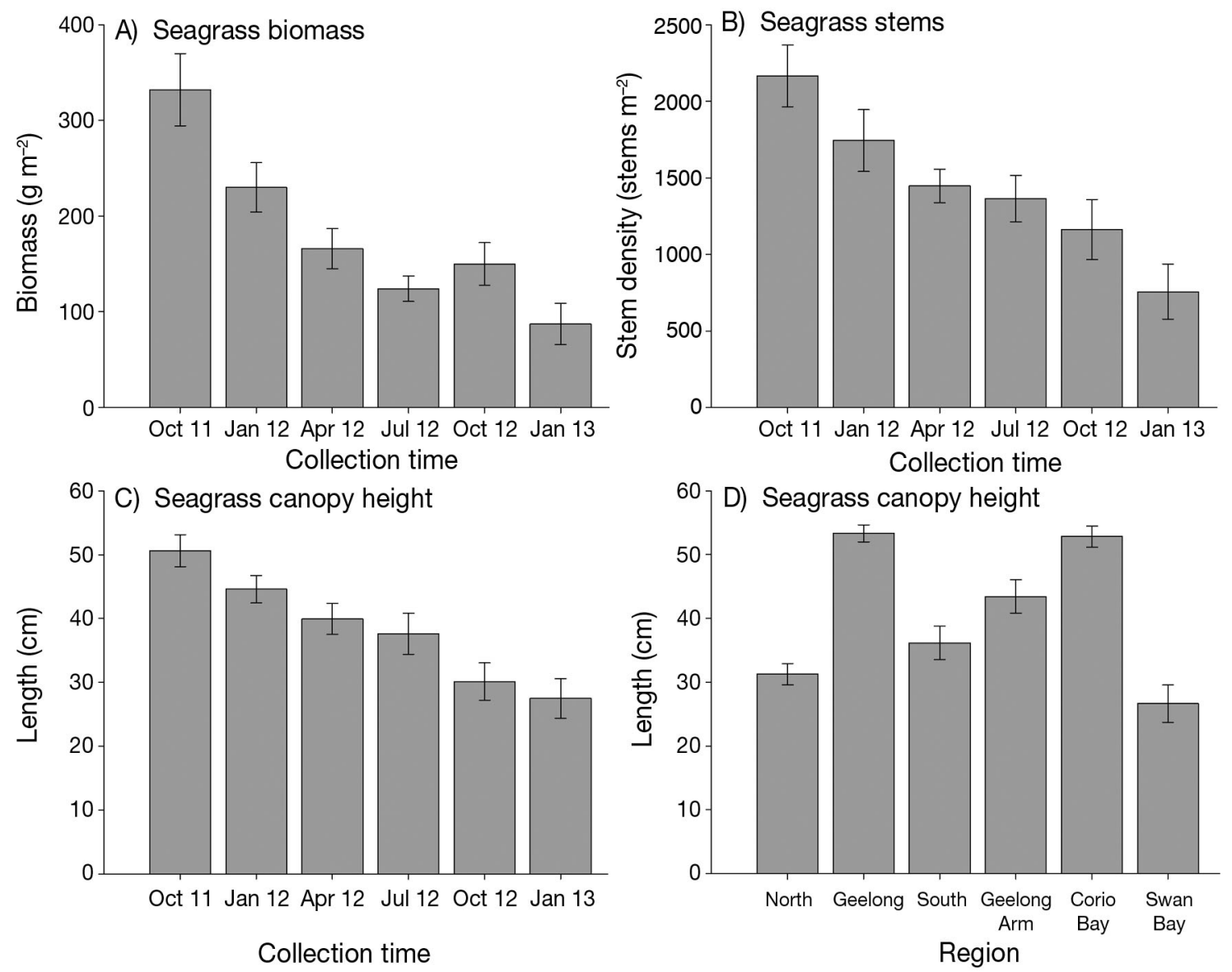

Fig. 4. Mean $( \pm \mathrm{SE})$ within-patch (A) seagrass biomass, (B) stem density and (C) canopy height at all sites across each sampling time, and (D) canopy height across regions. Collection times denote the month and year of collection

Moore 2010, Jenkins et al. 2015), providing a persistent seed bank over long periods, which may only recruit during optimal germination conditions. Such conditions may be infrequent, but over long periods the seed banks may still provide an important mechanism of recovery. Alternatively, bioturbation (Macreadie et al. 2014b) and seed predation (Rasheed 1999) from fauna have been suggested as inhibiting seedling establishment in disturbance treatments. Polychaete worms and crabs are common in Port Phillip Bay seagrass beds (Bird \& Jenkins 1999), and were frequently observed in disturbance plots and may have prevented seed survival and seedling establishment through predation, grazing or burial.

In contrast to sexual recovery, asexual recovery occurred quickly, with low intensity disturbance taking between 2 and 7 mo and high intensity disturbance between 2 and 13 mo. Asexual recovery times were similar to those recorded in similar experiments and small-scale natural disturbances (Creed \&
Amado Filho 1999, Rasheed 1999, Macreadie et al. 2014b), but shorter than for larger natural and experimental disturbances (Olesen et al. 2004, Boese et al. 2009) and those in a mixed tropical bed (Rollon et al. 1999). Small-scale disturbances facilitate asexual recovery as the edge to area ratio increases and neighbouring individuals quickly grow into the disturbed area. This growth may restrict sexual recovery, which requires time for seeds to germinate. In larger disturbances, seeds and vegetative fragments can reach the interior of the disturbance, providing an opportunity for seeds to colonise the disturbed area before neighbouring individuals can monopolise the space created by the disturbance. Once established, seedlings and fragments often grow vegetatively, enhancing the initial recovery through rhizome extension (Plus et al. 2003, Boese et al. 2009). Such patterns are consistent with other clonal systems where disturbance size influences colonisation rate and mechanisms (Keough 1984, Connell et al. 1985). 
Table 5. Results from regression analysis for seagrass asexual and regrowth recovery times against environmental variables. Initial belowground biomass was not removed in regrowth treatments and could not be tested

\begin{tabular}{|lcccccc|} 
& df & \multicolumn{2}{c}{ Asexual recovery } & \multicolumn{2}{c}{ Regrowth } \\
& & $F$ & $p$ & & $p$ \\
\hline Initial canopy height & 1 & 0.14 & 0.717 & 0.199 & 0.667 \\
Initial \% cover & 1 & 1.706 & 0.228 & 2.607 & 0.145 \\
Initial epiphytes & 1 & 1.067 & 0.332 & 3.323 & 0.106 \\
Initial aboveground biomass & 1 & 1.14 & 0.317 & 0.26 & 0.624 \\
(cut samples) & & & & & \\
Initial belowground biomass & 1 & 0.614 & 0.456 & - & - \\
\% Cover & 1 & 1.014 & 0.343 & 2.698 & 0.139 \\
Canopy height & 1 & 0.015 & 0.906 & 0.104 & 0.755 \\
Belowground biomass & 1 & 0.139 & 0.719 & 0.001 & 0.973 \\
Epiphyte & 1 & 0.802 & 0.397 & 2.2 & 0.176 \\
Aboveground biomass & 1 & 0.124 & 0.734 & 0.86 & 0.38 \\
Stems & 1 & 1.287 & 0.289 & 1.441 & 0.264 \\
Seeds & 1 & 0.202 & 0.665 & 0.013 & 0.912 \\
Organic matter & 1 & 0.025 & 0.878 & 0.149 & 0.71 \\
Coarse sand & 1 & 1.247 & 0.296 & 0.125 & 0.733 \\
Medium sand & 1 & 0.764 & 0.408 & 0.079 & 0.786 \\
Fine sand & 1 & 1.287 & 0.289 & 0.141 & 0.717 \\
Water temperature & 1 & 0.724 & 0.419 & 0.12 & 0.738 \\
Error & 8 & & & & \\
\hline
\end{tabular}

movement (Walker 1999, Jenkins et al. 2015). Such differences can determine large-scale seagrass distribution (Jenkins et al. 2015), but at the small scales examined in this study, localised hydrodynamic differences including patch and within-patch location may regulate sediment movement and nutrient accumulation (Jenkins et al. 2015, Ricart et al. 2015), causing variations in recovery. Similarly, genotypic diversity is thought to affect seagrass resilience (Hughes \& Stachowicz 2004, Reusch et al. 2005), and varies strongly across Port Phillip Bay, with genotypic diversity high in Corio Bay, the Geelong Arm, Blairgowrie and North Swan Bay, but low in northern Phillip Bay (North), Rosebud and South Swan Bay (Jenkins et al. 2015). However, resilience and recovery showed no relationship with genotypic diversity, and there was no evidence in this study to suggest that recovery is enhanced by genotypic diversity.

There were no consistent regional patterns in recovery; instead, there was strong variation across sites. Although seagrass canopy height was the only variable that was different across regions in the present study, concurrent studies demonstrated regional variation in reproductive effort and biomass, genotypic diversity, nutrient inputs, sediment movement and wave action (Jenkins et al. 2015, J. A. Hirst unpubl. data). Variation in recovery at the site but not regional level indicates that local conditions play a strong role in recovery. However, none of the seagrass patch characteristics measured could be linked to recovery at the site scale. Seagrass shading (via longer blades and higher density), higher reproductive effort or smothering by epiphytes can all affect seagrass growth and may affect recovery, but none of the variables we recorded showed any relationship with recovery. Factors such as hydrodynamics, sediment microbial communities, nutrient composition and patch age may also vary across sites, impacting recovery time, but they were not measured in this study. For instance, at regional scales, hydrodynamics in the form of wave heights and surface velocity vary significantly across Port Phillip Bay; the Geelong Arm and South regions are exposed to significant water and subsequent sediment movement, while in Swan Bay and Corio Bay there is little water
Within our study period there were significant declines in seagrass biomass, density and length across some patches. Although seagrass may show seasonal variation in biomass (Bulthuis \& Woelkerling 1983), we saw clear declines in meadows where experiments took place, including in control plots at many sites. This was particularly evident at North Swan Bay, Blairgowrie and Kirk Point, where seagrass cover in some control plots approached zero. Declines in control plots led to convergence between treatment and control plots before treatments reached original levels, and contributed to faster than expected recovery at these sites. These declines may have masked regional differences in recovery as treatments returned to lowered control levels before any regional differences became apparent.

Overall, seagrass recovery occurs consistently through vegetative growth from small-scale disturbances in Port Phillip Bay. At all sites, asexual recovery was the primary mode of recovery and could not be attributed to any environmental properties we measured. In contrast, sexual recovery did not contribute to recovery regardless of the presence of seeds and spathes nearby.

Acknowledgements. This work was funded by the Department of Environment, Land, Water and Planning (Australia). 
P.I.M. was supported by Australian Research Council Discovery Early Career Researcher Award DE130101084. Additional support came from Discovery Award DP1093230 to M.J.K. All work was performed at the Victorian Marine Science Consortium. Assistance in the field and laboratory was provided by E. Cumming, R. Watson, D. Lees, A. Wayman and P. Ho.

\section{LITERATURE CITED}

Adger WN, Hughes TP, Folke C, Carpenter SR, Rockström J (2005) Social-ecological resilience to coastal disasters. Science 309:1036-1039

Andersen T, Carstensen J, Hernandez-Garcia E, Duarte CM (2009) Ecological thresholds and regime shifts: approaches to identification. Trends Ecol Evol 24:49-57

- Anthony KRN, Marshall PA, Abdulla A, Beeden R and others (2015) Operationalizing resilience for adaptive coral reef management under global environmental change. Glob Change Biol 21:48-61

Ball D, Soto-Berelov M, Young P (2014) Historical seagrass mapping in Port Phillip Bay, Australia. J Coast Conserv 18:257-272

Barbier EB, Hacker SD, Kennedy C, Koch EW, Stier AC, Silliman BR (2011) The value of estuarine and coastal ecosystem services. Ecol Monogr 81:169-193

> Becheler R, Diekmann O, Hily C, Moalic Y, Arnaud-Haond S (2010) The concept of population in clonal organisms: mosaics of temporally colonized patches are forming highly diverse meadows of Zostera marina in Brittany. Mol Ecol 19:2394-2407

> Bintz JC, Nixon SW (2001) Responses of eelgrass Zostera marina seedlings to reduced light. Mar Ecol Prog Ser 223:133-141

Bird FL, Jenkins GP (1999) Abundance, biomass and estimated production of invertebrate fauna associated with seagrass, Heterozostera tasmanica, in Swan Bay and an adjacent area of Port Phillip Bay, Victoria. Proc R Soc Vic 111:1-13

Blake S, Ball D (2001) Seagrass mapping Port Phillip Bay. Marine and Freshwater Resources Institute Report, Queenscliff, Vic

Boese BL, Kaldy JE, Clinton PJ, Eldridge PM, Folger CL (2009) Recolonization of intertidal Zostera marina L. (eelgrass) following experimental shoot removal. J Exp Mar Biol Ecol 374:69-77

> Bryson ES, Trussell GC, Ewanchuk PJ (2014) Broad-scale geographic variation in the organization of rocky intertidal communities in the Gulf of Maine. Ecol Monogr 84: 579-597

Bulthuis DA, Woelkerling WJ (1983) Seasonal variation in standing crop, density and leaf growth rate of the seagrass, Heterozostera tasmanica, in Western Port and Port Phillip Bay, Victoria, Australia. Aquat Bot 16:111-136

> Conacher CA, Poiner IR, Butler J, Pun S, Tree DJ (1994) Germination, storage and viability testing of seeds of Zostera capricorni Aschers. from a tropical bay in Australia. Aquat Bot 49:47-58

Connell JH, Keough MJ, Pickett STA, White PA (1985) Disturbance and patch dynamics of subtidal marine animals on hard substrata. Academic Press, San Diego, CA

Creed JC, Amado Filho GM (1999) Disturbance and recovery of the macroflora of a seagrass (Halodule wrightii Ascherson) meadow in the Abrolhos Marine National
Park, Brazil: an experimental evaluation of anchor damage. J Exp Mar Biol Ecol 235:285-306

Erftemeijer PLA, Koch EW (2001) Sediment geology methods for seagrass habitat. In: Short FT, Coles RG (eds) Global seagrass research methods. Elsevier Science B. V., Amsterdam

> Folke C, Carpenter S, Walker B, Scheffer M, Elmqvist T, Gunderson L, Holling C (2004) Regime shifts, resilience, and biodiversity in ecosystem management. Annu Rev Ecol Evol Syst 35:557-581

Frederiksen M, Krause-Jensen D, Holmer M, Laursen JS (2004) Long-term changes in area distribution of eelgrass (Zostera marina) in Danish coastal waters. Aquat Bot 78 : 167-181

Fukami T, Nakajima M (2011) Community assembly: alternative stable states or alternative transient states? Ecol Lett 14:973-984

Holon F, Boissery P, Guilbert A, Freschet E, Deter J (2015) The impact of 85 years of coastal development on shallow seagrass beds (Posidonia oceanica L. (Delile)) in South Eastern France: a slow but steady loss without recovery. Estuar Coast Shelf Sci 165:204-212

Hughes AR, Stachowicz JJ (2004) Genetic diversity enhances the resistance of a seagrass ecosystem to disturbance. Proc Natl Acad Sci USA 101:8998-9002

Hughes TP, Graham NAJ, Jackson JBC, Mumby PJ, Steneck RS (2010) Rising to the challenge of sustaining coral reef resilience. Trends Ecol Evol 25:633-642

Jacobs SWL, Les DH (2009) New combinations in Zostera (Zosteraceae). Telopea 12:419-423

Jarvis JC, Moore KA (2010) The role of seedlings and seed bank viability in the recovery of Chesapeake Bay, USA, Zostera marina populations following a large-scale decline. Hydrobiologia 649:55-68

> Jarvis J, Moore K (2015) Effects of seed source, sediment type, and burial depth on mixed-annual and perennial Zostera marina L. seed germination and seedling establishment. Estuar Coast 38:964-978

Jenkins GP, Keough MJ, Ball D, Cook PLM and others (2015) Seagrass resilience in Port Phillip Bay. University of Melbourne, Melbourne

Kendrick GA, Waycott M, Carruthers TJB, Cambridge ML and others (2012) The central role of dispersal in the maintainance and persistence of seagrass populations. Biosience 62:56-65

Keough MJ (1984) Effects of patch size on the abundance of sessile marine invertebrates. Ecology 65:423-437

> Lee R, Black K, Bosserel C, Greer D (2012) Present and future prolonged drought impacts on a large temperate embayment: Port Phillip Bay, Australia. Ocean Dyn 62:907-922

- Macreadie PI, Baird ME, Trevathan-Tackett SM, Larkum AWD, Ralph PJ (2014a) Quantifying and modelling the carbon sequestration capacity of seagrass meadows a critical assessment. Mar Pollut Bull 83:430-439

> Macreadie PI, York PH, Sherman CDH (2014b) Resilience of Zostera muelleri seagrass to small-scale disturbances: the relative importance of asexual versus sexual recovery. Ecol Evol 4:450-461

- Macreadie PI, York PH, Sherman CDH, Keough MJ, Ross DJ, Ricart AM, Smith TM (2014c) No detectable impact of small-scale disturbances on 'blue carbon' within seagrass beds. Mar Biol 161:2939-2944

> Martins GM, Jenkins SR, Ramirez R, Tuya F, Neto AI, Arenas F (2014) Early patterns of recovery from disturbance in intertidal algal assemblages: consistency across re- 
gions within a marine province. Mar Ecol Prog Ser 517: 131-142

McKenzie LJ, Campbell SJ, Roder CA (2003) SeagrassWatch: manual for mapping \& monitoring seagrass resources by community (citizen) volunteers. Queensland Fisheries Services, Northern Fisheries Centre, Cairns

Moore KA, Orth RJ, Nowak JF (1993) Environmental regulation of seed germination in Zostera marina L. (eelgrass) in Chesapeake Bay: effects of light, oxygen and sediment burial. Aquat Bot 45:79-91

Navarrete SA, Wieters EA, Broitman BR, Castilla JC (2005) Scales of benthic-pelagic coupling and the intensity of species interactions: from recruitment limitation to topdown control. Proc Natl Acad Sci USA 102:18046-18051

Olesen B, Marba N, Duarte CM, Savela RS, Fortes MD (2004) Recolonization dynamics in a mixed seagrass meadow: the role of clonal versus sexual processes. Estuaries 27:770-780

Orth RJ, Harwell MC, Baily EM, Bartholomew A and others (2000) A review of issues in seagrass seed dormancy and germination: implications for conservation and restoration. Mar Ecol Prog Ser 200:277-288

Orth RJ, Carruthers TJB, Dennison WC, Duarte CM and others (2006a) A global crisis for seagrass ecosystems. Bioscience 56:987-996

Orth RJ, Luckenbach ML, Marion SR, Moore KA, Wilcox DJ (2006b) Seagrass recovery in the Delmarva Coastal Bays, USA. Aquat Bot 84:26-36

Plus M, Deslous-Paoli JM, Dagault F (2003) Seagrass (Zostera marina L.) bed recolonisation after anoxiainduced full mortality. Aquat Bot 77:121-134

Quinn GP, Keough MJ (2002) Experimental design and data analysis for biologists. Cambridge University Press, Cambridge

Rasheed MA (1999) Recovery of experimentally created gaps within a tropical Zostera capricorni (Aschers.) sea-

Editorial responsibility: Kenneth Heck Jr., Dauphin Island, Alabama, USA grass meadow, Queensland Australia. J Exp Mar Biol Ecol 235:183-200

Rasheed MA (2004) Recovery and succession in a multispecies tropical seagrass meadow following experimental disturbance: the role of sexual and asexual reproduction. J Exp Mar Biol Ecol 310:13-45

> Rasheed MA, McKenna SA, Carter AB, Coles RG (2014) Contrasting recovery of shallow and deep water seagrass communities following climate associated losses in tropical north Queensland, Australia. Mar Pollut Bull 83: 491-499

Reusch TBH, Ehlers A, Hammerli A, Worm B (2005) Ecosystem recovery after climatic extremes enhanced by genotypic diversity. Proc Natl Acad Sci USA 102:2826-2831

> Ricart AM, Dalmau A, Pérez M, Romero J (2015) Effects of landscape configuration on the exchange of materials in seagrass ecosystems. Mar Ecol Prog Ser 532:89-100

Rollon RN, Van Steveninck EDD, Van Vierssen W, Fortes MD (1999) Contrasting recolonization strategies in multispecies seagrass meadows. Mar Pollut Bull 37:450-459

Short FT, Polidoro B, Livingstone SR, Carpenter KE, and others (2011) Extinction risk assessment of the world's seagrass species. Biol Conserv 144:1961-1971

Walker SJ (1999) Coupled hydrodynamic and transport models of Port Phillip Bay, a semi-enclosed bay in southeastern Australia. Mar Freshw Res 50:469-481

> Waycott M, Duarte CM, Carruthers TJB, Orth RJ and others (2009) Accelerating loss of seagrasses across the globe threatens coastal ecosystems. Proc Natl Acad Sci USA 106:12377-12381

Zipperle AM, Coyer JA, Reise K, Gitz E, Stam WT, Olsen JL (2009) Clonal architecture in an intertidal bed of the dwarf eelgrass Zostera noltii in the Northern Wadden Sea: persistence through extreme physical perturbation and the importance of a seed bank. Mar Biol 156: 2139-2148

Submitted: August 7, 2015; Accepted: October 26, 2015 Proofs received from author(s): December 16, 2015 